\title{
Hierarchy and subsurface correlation of muddy baffles in lacustrine delta fronts: a case study in the X Oilfield, Subei Basin, China
}

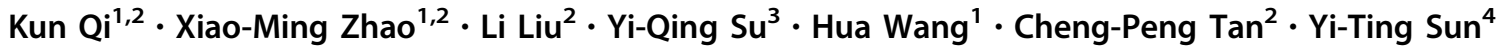

Received: 1 November 2017 / Published online: 11 July 2018

(C) The Author(s) 2018

\begin{abstract}
Muddy baffles are one of the major geological factors controlling the underground fluid flow as well as the remaining oil distribution. This study used detailed drilling data from the $\mathrm{E}_{1} f_{1}$ reservoir in the X Oilfield, Subei Basin, China, to investigate the hierarchical muddy baffles developed on lacustrine delta fronts and their precise cross-well correlation. According to the theories on allogenic and autogenic cycles as well as the genesis and scales of muddy baffles, five orders of muddy baffles were classified, which provided various degrees of difficulty when attempting interwell correlation. Under the guidance of a reliable stratigraphic model, the precise cross-well correlation of muddy baffles could be achieved and the key point of establishment of this stratigraphic model was to calculate foreset angles of hierarchical muddy baffles during deposition. During calculation, the relationships between sediment flow direction, higher-order strata dipping direction, well types and well trajectory direction should all be taken into consideration and some other angles (referred to here as $\theta_{1}$, $\theta_{2}$ and $\theta_{3}$ ) should also be measured. Such new methods of cross-well correlation for hierarchical muddy baffles could greatly reduce the uncertainties and multiple solutions, which in turn would be significant for efficient development and oil recovery enhancement in the reservoirs.
\end{abstract}

Keywords Delta front muddy $\cdot$ Baffle $\cdot$ Genetic analysis $\cdot$ Hierarchy division $\cdot$ Strata correlation

\section{Introduction}

Muddy baffles refer to the non-permeable or poorly permeable mud rocks (Geehan et al. 1986; Zhang et al. 2004; Shu 2006), which include mudstone, silty mudstone and argillaceous siltstone in terms of lithology. They are usually well-identified physical interfaces, formed due to weakened hydrodynamic conditions of sedimentation

Edited by Jie Hao

Xiao-Ming Zhao

zhxim98@163.com

1 State Key Laboratory of Oil and Gas Reservoir Geology and Exploitation, Southwest Petroleum University, Chengdu 610500, Sichuan, China

2 School of Geoscience and Technology, Southwest Petroleum University, Chengdu 610500, Sichuan, China

3 School of Geoscience, Yangtze University, Wuhan 430100, Hubei, China

4 PetroChina Southwest Oil and Gasfield Company, Chengdu 610500, Sichuan, China
(Tripsanas et al. 2004; Olariu 2006; Smart et al. 2009). Their thickness and spatial distribution vary significantly due to the influence of different marine (lacustrine) flooding scales and sedimentary environment changes (Miall 1988). Some of them can be as thick as several to tens of meters, covering a vast area of tens to hundreds of square kilometers, while some are only as thick as several to tens of centimeters, with a limited distribution range of less than one square kilometer; further smaller ones could be roughly on the same scale as laminas, which could only be clearly observed in hand specimen ( $\mathrm{Li}$ et al. 2007; Guo 2011).

Muddy baffles greatly control the underground fluid flow and remaining oil distribution in reservoirs (Weber 1986; Ainsworth et al. 1999; Jackett et al. 2014), especially in the middle and later stages of water flooding development, as they can seal the fluids in the vertical and (or) lateral directions (Willis and White 2000). Therefore, fine investigation of spatial distribution of hierarchical muddy baffles is of great importance for the accurate prediction of highly complex remaining oil distribution (Jackson and Muggeridge 2000; Larue and Legarre 2004; Escalona and 
Mann 2006). However, it is still impossible to detect the lamina-scale muddy baffles due to limited resolution of geophysical data. Decimeter-to-meter-scale muddy baffles can be easily identified in the single-well logging data, but their correlation among wells is highly uncertain $(\mathrm{Li}$ and White 2003), which greatly hinders the efficient development of oilfields (Xu et al. 2012; Zhao et al. 2016).

Taking the $\mathrm{E}_{1} f_{1}$ reservoir of the X Oilfield, Subei Basin as an example, this study analyzed the uncertainty of hierarchical muddy baffle correlation based on the sequence stratigraphy theory and proposed a new method to establish stratigraphic development models in lacustrine delta fronts by calculating foreset bed angles utilizing drilling data. Such new method could effectively guide the fine cross-well correlation of foreset beds (baffles) and thus offer important practical reference for efficient development and oil recovery enhancement in this kind of reservoir.

\section{Geological setting}

\subsection{Location}

The Subei Basin refers to the onshore part of the SubeiSouth Yellow Sea Basin. It is adjacent to the Tanlu Fault and the Lusu Uplift in the west, the Sunan Uplift in the South and the Yellow Sea to the east. The east-west extending uplift separates the basin into three secondary units, namely the Dongtai Depression in the south, Yanfu Depression in the north and the Jianhu Uplift in the middle. Within each depression, there are several sags and low uplifts (Bao et al. 2013; Wu et al. 2017) (Fig. 1a). The X Oilfield is in the Dayiji Structure in the west of the north slope in the Gaoyou Sag, which is a south-lifting-northtilting faulted-nose structure reversely sealed by the Normal Fault 1 (Fig. 1b).

\subsection{Geological background}

The Subei Basin is a Tertiary terrestrial petroliferous basin, which has gone through three development stages, respectively, corresponding to formation of depressions, faulted sags and again depressions (Qian 2001; Qiu et al. 2006). The Paleocene Funing Formation, the target of this study, was deposited during the earlier depression stage (83.0-54.9 Ma), when the Yizheng Orogeny led to westward water flooding on the rugged topography as well as an enlarged lake area and deeper water body. Then, the basin entered the fault depression stage due to the influence of the Wubao Tectonic Movement.

The Funing Formation can be divided into four members from the bottom up, namely the coarse $\mathrm{E}_{1} f_{1}$, fine $\mathrm{E}_{1} f_{2}$, coarse $E_{1} f_{3}$ and fine $E_{1} f_{4}$, which make up two sourcereservoir-cap assemblages (Liu et al. 2016). $\mathrm{E}_{1} f_{1}$ is a set of fluvial-deltaic deposits, with a lithology of mainly sandstone interbedded with mudstone and a thickness of $0-1000 \mathrm{~m}$, which serve as the main reservoirs; $\mathrm{E}_{1} f_{2}$ is identified as a set of lacustrine deposits, with dark grayblack mudstones intercalated with marls and thin limestone and dolomite, 0-350 $\mathrm{m}$ thick, serving as the source rocks distributed throughout the basin; $\mathrm{E}_{1} f_{3}$ is a set of deltaic deposits, with lithology of gray-dark gray mudstone interbedded with silt-fine sandstone and a thickness of 0-300 m, and it is also one set of important reservoirs; $\mathrm{E}_{1} f_{4}$ is a set of lacustrine dark mudstones with a thickness of 0-500 $\mathrm{m}$, acting as good source rocks. The Wubao Tectonic Movement resulted in the differential erosion of the upper part of $\mathrm{E}_{1} f_{4}$ in most areas (Fig. 2), and the remaining thickness varies in different areas.

The target layer is in the $\mathrm{E}_{1} f_{1}$, corresponding to Gilberttype delta front deposits (Yin et al. 2009; Ji et al. 2013). The segment RQ shows up in the CM diagram, indicating the dominant saltation transportation of detrital components (Fig. 3a). Therefore, it can be inferred that deltas in this area are medium-sized ones with gentle fluvial slope and relatively short river length. The lithologies are mainly light gray-light brown arkosic lithic coarse silty quartz sandstones and fine sandstones. Mineral contents are identified in the thin sections: quartz (59\%-61.2\%), orthoclase $(9.7 \%-11.6 \%)$, plagioclase $(6.1 \%-7.8 \%)$ and lithic fragments $(20.9 \%-22.3 \%)$. Deposits are featured by low compositional maturity, good sorting, sub-rounded to sub-angular roundness (Fig. 3b), low structural maturity, and occasional quartz and feldspar secondary overgrowths. The sand bodies are generally less than $4 \mathrm{~m}$ thick, intercalated with mudstones in thin layers. Such deposits can be classified as high porosity, medium permeability reservoirs, with the respective average porosities and permeabilities of $23.5 \%$ and $192 \times 10^{-3} \mu^{2}$ measured by core analysis.

\section{Analysis of hierarchical muddy baffles}

\subsection{Theoretical basis}

Influenced by hierarchical tectonic activities and climate changes, the base level presents different hierarchical characteristics. Its rise and fall comprise hierarchical cycles, referred to as allogenic cycles ( $\mathrm{Ji}$ et al. 2012), corresponding to the parasequence, parasequence set and sequence in the low to high hierarchical order as divided in the classic sequence stratigraphy theory (Vail 1987), or the long-, medium-, short-term cycles as proposed by Cross et al. (1992). The start or end of one cycle generally corresponds to the deposition of hierarchical muddy baffles. 

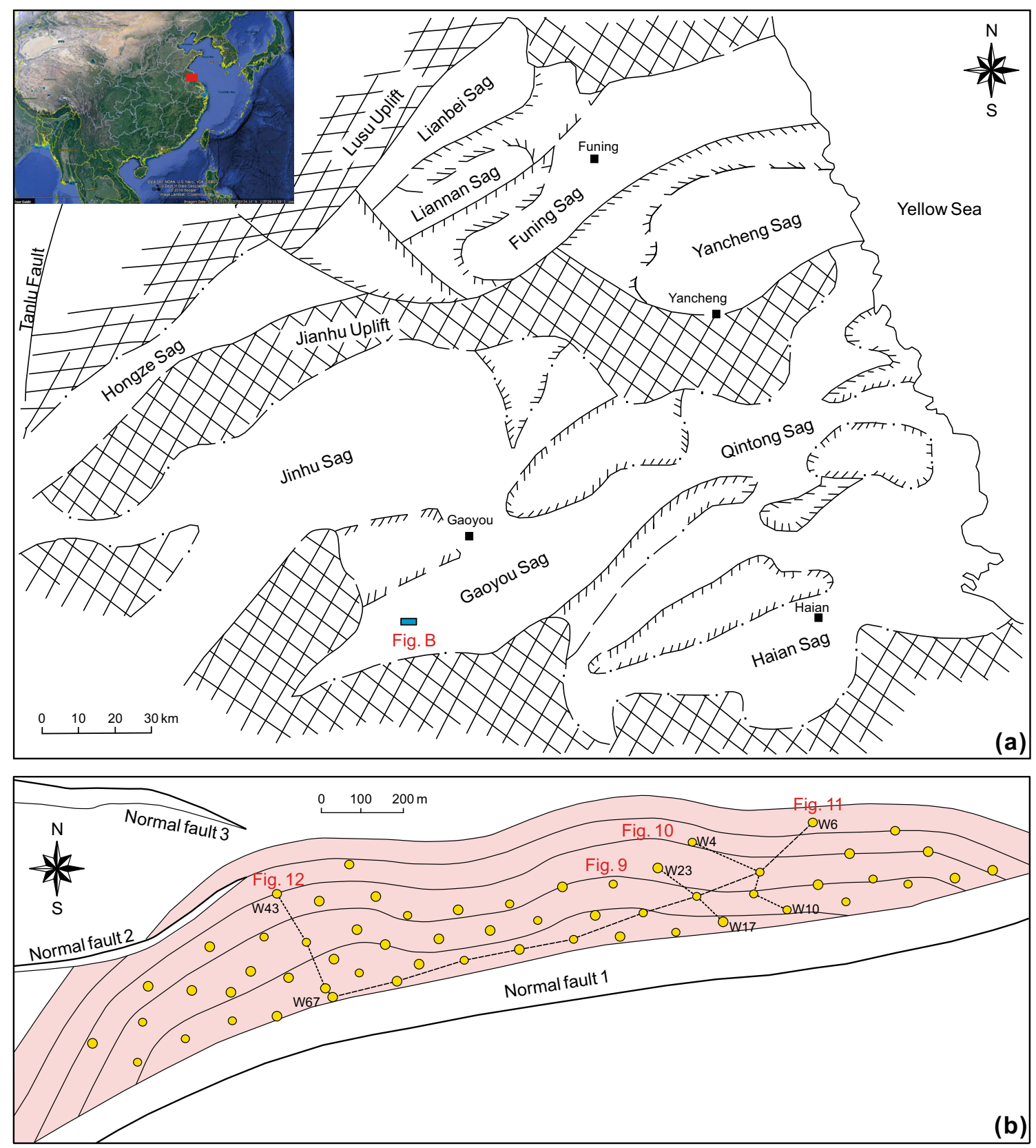

Fig. 1 a Division of tectonic units of the Subei Basin. The blank and shadow sections represent the sags and uplifts of the basin, respectively, showing the target oilfield is located on the north slope of the Gaoyou Sag. The inset shows the location of the Subei Basin in the world. b Structure diagram of the top surface of $E_{1} f_{1}$ reservoir

In addition to allogenic cycles, there are some other cycles uncontrolled by the base level variation, which are referred to as autogenic cycles (Ji et al. 2012). Such cycles are commonly controlled by several factors. (1) Variation of hydrodynamics. For instance, suddenly increased hydrodynamics at the delta front can lead to bifurcation and avulsion of underwater distributary channels and thus the lateral migration of delta lobes. (2) Terrain factors, showing that the X Oilfield is in a south-lifting-north-tilting faultednose structure reversely sealed by the Normal Fault 1 (referred to here as the Dayiji Structure). The yellow points represent the locations of wells and also shown are the connecting-well profiles of Figs. 9, 10, 11 and 12 as well as three major normal faults

including relief, gradient and slope direction. For example, the delta lobes generally migrate more quickly in the steep areas, while more slowly in the gentle areas where allogenic factors dominate. (3) Stability and vegetation of the provenance. In the stable and highly vegetated provenance, autogenic effects are weak as there are fewer landslides and debris flows. (4) Other factors such as earthquakes, tsunamis and other events that cause turbidity and debris flow. 


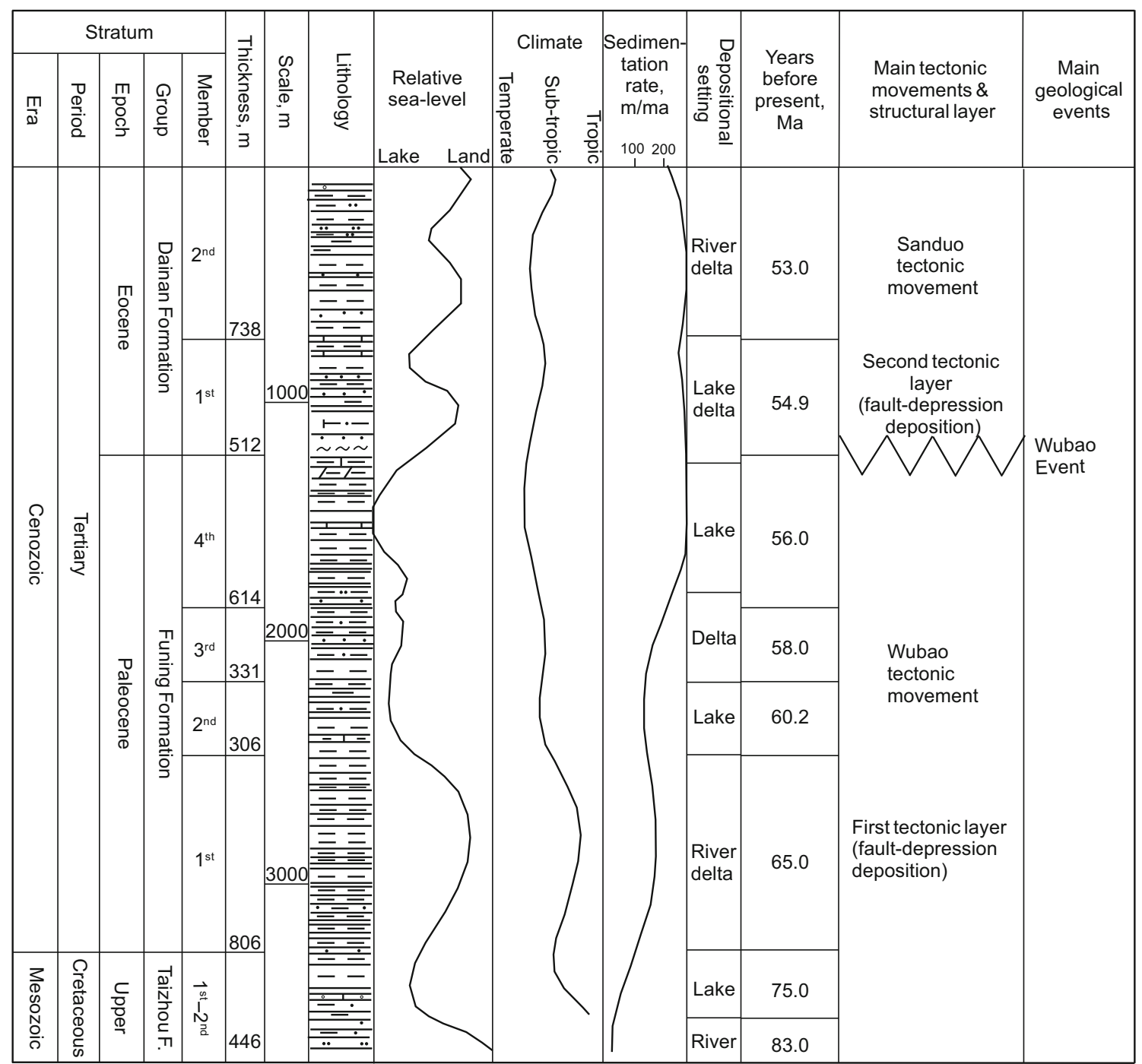

Fig. 2 Stratigraphic column of the Cretaceous-Tertiary of the Subei Basin. The first member of the Funing Formation, with mainly sandstone interbedded with mudstone lithology, is our study interval.

Autogenic forcing can contribute to the hierarchical muddy baffles within or between single genetic units, such as those within or between the individual mouth bars.

Therefore, it can be concluded that there are several hierarchies of muddy baffles due to the common effects of hierarchical autogenic and allogenic forcing, which lay the theoretical basis for muddy baffle hierarchy analysis.

\subsection{Hierarchy division of muddy baffles}

Given the genesis associated with allogenic or autogenic cycles, scales, lithological characteristics and corresponding $\log$ responses, muddy baffles in the Paleocene, Funing Formation, X Oilfield were classified into five hierarchies which could also coincide with other interfaces or strata units (Table 1).
Some other geological conditions like ages, sea-level changes, climatic changes, sedimentary facies as well as the tectonic movements are also shown

The first-order muddy baffles refer to those on the top of $\mathrm{E}_{1} f_{1}$ (Fig. 2), which are gray mudstones formed between oil-bearing beds during the maximum flooding period, interbedded with thin silty mudstone and argillaceous siltstone. They are stably distributed, extending tens of kilometers. Their thicknesses range from 5 to $8 \mathrm{~m}$, with relatively strong sealing properties. In the logging curves, they coincide with the base line of spontaneous potential and high natural gamma value (about 130 API) (Fig. 4). Their development was deduced to be controlled by the long-term base level cycles (third-order sequence). The tropical to subtropical climate change as well as the uplifting to subduction transition commonly contributed to the maximum lacustrine flooding in the Subei Basin, which resulted in the first-order muddy baffles. They are 
(a)

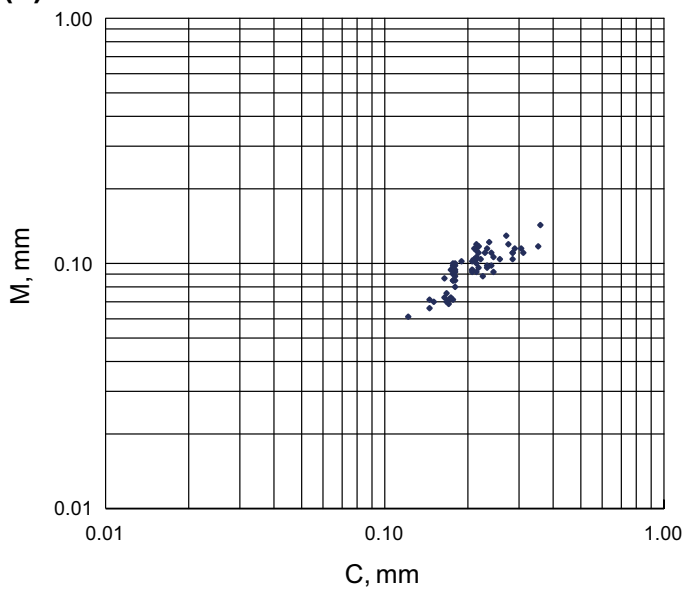

(b)

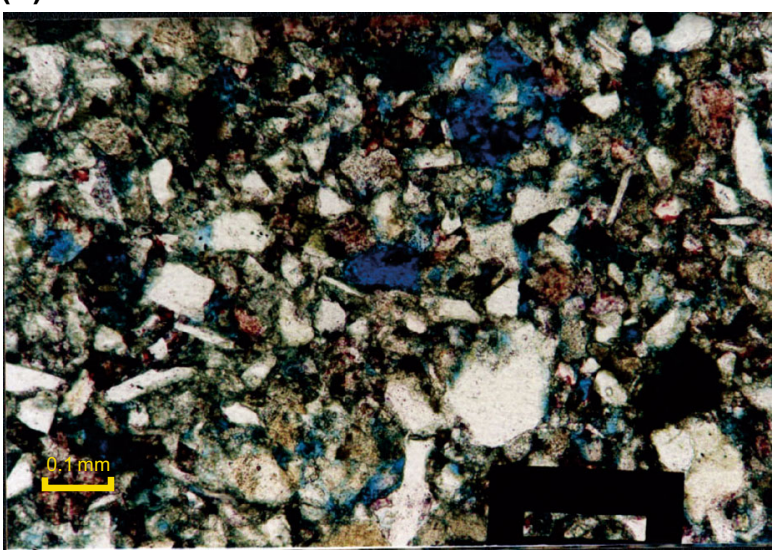

Fig. $3 \mathrm{CM}$ diagram (a) and the typical casting thin section (b) form the samples of $\mathrm{E}_{1} f_{1}$ reservoir. There is a noticeable segment RQ in the $\mathrm{CM}$ diagram (a), representing the dominant saltation transportation of detrital components. In the casting thin section (b), good sorting, subrounded to sub-angular roundness and occasional secondary overgrowths of quartz and feldspar can be observed

Table 1 Hierarchical muddy baffles and their correlations with other strata units

\begin{tabular}{|c|c|c|c|c|c|}
\hline $\begin{array}{l}\text { Hierarchical } \\
\text { muddy baffles }\end{array}$ & $\begin{array}{l}\text { Hierarchical } \\
\text { architecture interfaces } \\
\text { (Miall) }\end{array}$ & $\begin{array}{l}\text { Sequence boundaries of classical } \\
\text { sequence stratigraphy (Vail) }\end{array}$ & $\begin{array}{l}\text { Base level cycles of high-resolution } \\
\text { sequence stratigraphy (Cross) }\end{array}$ & $\begin{array}{l}\text { Oil layer } \\
\text { units }\end{array}$ & $\begin{array}{l}\text { Type of } \\
\text { cycles }\end{array}$ \\
\hline $1 \mathrm{st}$ & 7 th & Sequence & Long-term cycle & $\begin{array}{c}\text { Oil-bearing } \\
\text { sequence }\end{array}$ & $\begin{array}{l}\text { Allogenic } \\
\text { cycle }\end{array}$ \\
\hline 2nd & 6th & Parasequence set & Middle-term cycle & $\begin{array}{l}\text { Oil-bearing } \\
\text { beds }\end{array}$ & \\
\hline 3 rd & 5 th & Parasequence & Short-term cycle & Sand group & \\
\hline 4th & 4 th & & & $\begin{array}{l}\text { Single } \\
\text { layer }\end{array}$ & $\begin{array}{l}\text { Autogenic } \\
\text { cycle }\end{array}$ \\
\hline 5 th & $3 \mathrm{rd}$ & & & $\begin{array}{c}\text { Individual } \\
\text { oil pay }\end{array}$ & \\
\hline
\end{tabular}

comparable to the seventh-order interface by Miall (1988) and are allogenic-cycle-related interfaces.

The second-order muddy baffles are between the sand groups of $\mathrm{E}_{1} f_{1}$ (Fig. 2), which are light gray mudstones and silty mudstones deposited during the secondary flooding (Fig. 4b). They are stably distributed, extending several kilometers with thicknesses ranging from 3 to $4 \mathrm{~m}$. They are also featured by the base line of spontaneous potential and high natural gamma value (about 115 API) (Fig. 4). Their development is thought to be controlled by the medium-term base level cycles (parasequence set), corresponding to the subprime flooding surface in the cyclic lacustrine water level fluctuations. They are comparable to the sixth-order interface of Miall (1988) and are also allogenic-cycle-related interfaces.

The third-order muddy baffles are light gray mudstones, silty mudstones and argillaceous siltstones (Fig. 4b), which have a thickness range of $0.7-1.5 \mathrm{~m}$ and are characterized by weak return in the $S P$ curves and large variation (90-115 API) in the natural gamma ray curves. Local and temporary environment changes resulted in the fluctuation of lake level and the occurrence of intermittent flooding, which in turn caused the deposition of lobe complexes and associated major sand sheet interfaces, i.e., the muddy baffles. Therefore, the third-order muddy baffles were probably controlled by the short-term base level cycles (parasequence) and to some degree modified by autogenic forcing. In addition, it is comparable to the fifth-order interface of Miall (1988).

The fourth-order muddy baffles are light gray mudstones, silty mudstones and argillaceous siltstones (Fig. 4b), with a thickness range of $0.4-1 \mathrm{~m}$. They are too thin to be recognized in the $S P$ curves, but they present certain amplitude differences (80-90 API) in the natural gamma ray curves. Their development was controlled by the variation of hydrodynamics, which resulted in the 


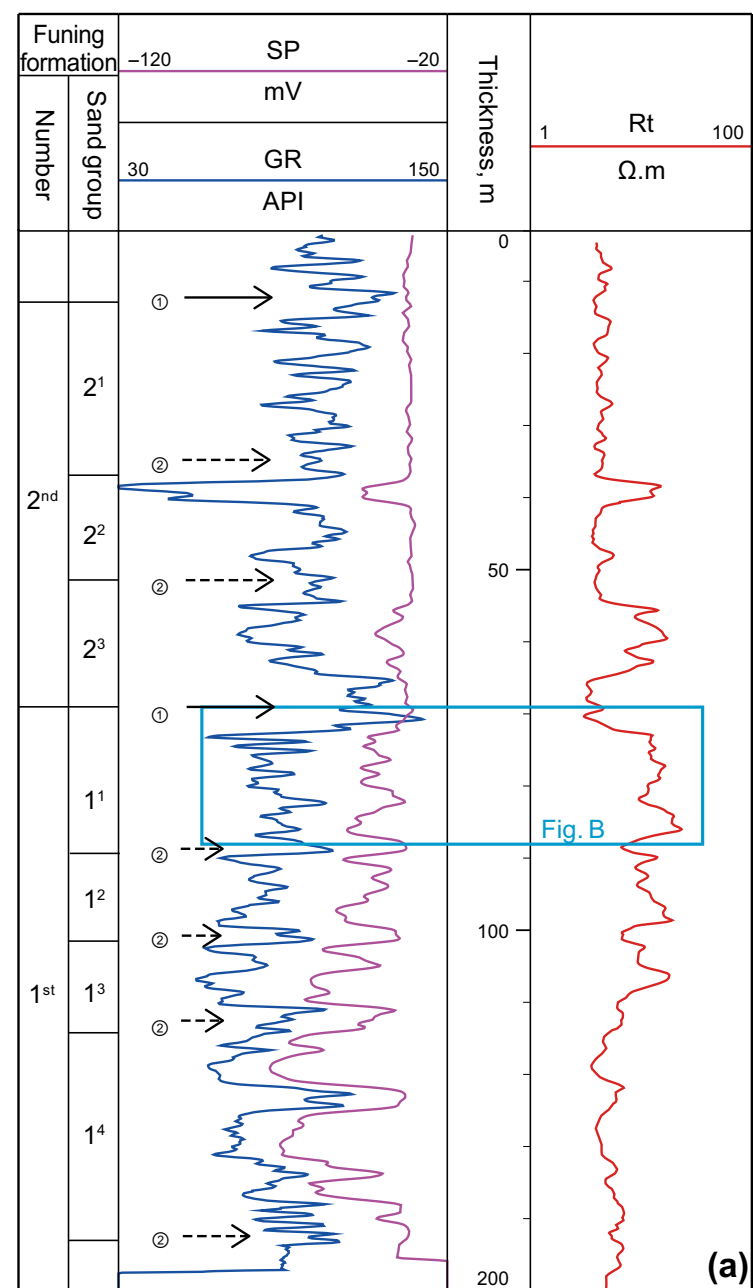

Fig. 4 Five orders of muddy baffles and their corresponding log responses as well as lithological characteristics. The first two orders are mainly shown in a, and others are shown in $\mathbf{b}$, the close-up of the top sand group of the first member, Funing Formation. The log responses refer to the spontaneous potential curve (SP), natural

avulsion and bifurcation of underwater distributary channels and further the lateral migration of delta front lobes. These baffles were then formed between lobes, above which are large-scale scouring surfaces. They are comparable to the fourth-order interface of Miall (1988) and are autogenic-cycle-related interfaces.

The fifth-order muddy baffles are light gray mudstones, silty mudstones and argillaceous siltstones (Fig. 4b), with thicknesses of only $0.3-0.5 \mathrm{~m}$. Influenced by surrounding rocks, there are some weak returns in the natural gamma ray curves. They were developed within single-lobe bodies, and they are actually accretion units formed in the constant progradation of lobes toward the lacustrine basin center. The interface of adjacent units indicates a short-term temporarily static water environment, above which are large-scale scouring surfaces. They are comparable to the

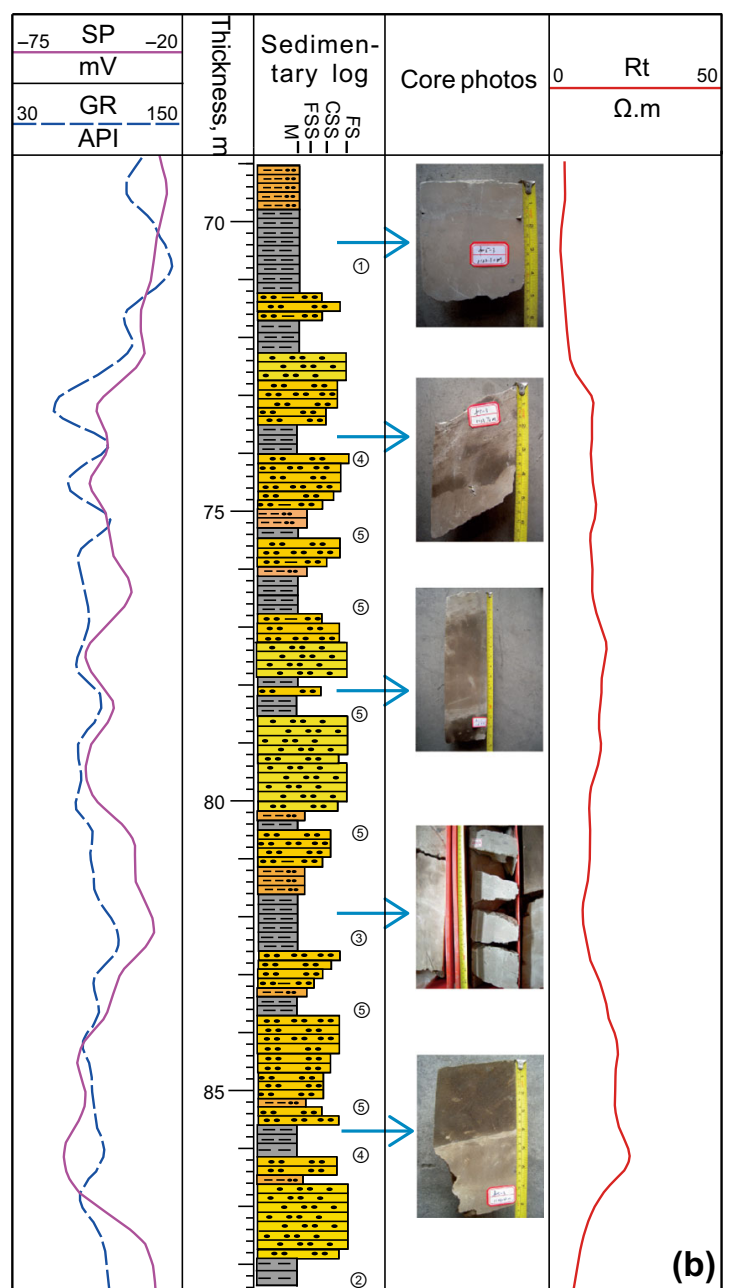

gamma ray curve (GR) as well as the resistivity curve $(R t)$, and the lithological features are characterized by core photographs and the sedimentary $\log$, with M, FSS, CSS and FS representing mudstone, fine siltstone, coarse siltstone and fine sandstone, respectively

third-order interface of Miall (1988) and are autogeniccycle-related interfaces.

\section{Cross-well correlation of hierarchical muddy baffles}

\subsection{Various degrees of difficulties in implementing cross-well correlation}

Although hierarchical muddy baffles are isochronous and can be easily identified in single wells, their distribution is relatively unstable laterally, leading to various degrees of difficulties in implementing cross-well correlation (Table 2).

Higher-order muddy baffles, such as the first- and second-order ones, are generally featured by large distribution 
Table 2 Controlling factors and correlation difficulties of five orders of muddy baffles

\begin{tabular}{llll}
\hline $\begin{array}{l}\text { Broad } \\
\text { hierarchies }\end{array}$ & $\begin{array}{l}\text { Hierarchical muddy } \\
\text { baffles }\end{array}$ & Controlling factors & $\begin{array}{l}\text { Difficulties of } \\
\text { correlation }\end{array}$ \\
\hline Higher order & 1 st & $\begin{array}{c}\text { Allogenic cycles controlled by large-scale tectonic movements and } \\
\text { climatic changes }\end{array}$ & Easy \\
Medium order & 3rd & Allogenic cycles influenced by autogenic forcing & Hard \\
Low order & 4 th & Autogenic cycle & Very hard \\
& 5 th & & \\
\hline
\end{tabular}

area and stable thickness, and thus, they can be easily traced and correlated between wells within the depression or reservoir.

However, the lower-order muddy baffles, such as the fourth- and fifth ones, have smaller distribution areas and higher lateral discontinuity, making cross-well correlation of them more difficult. Specifically, their distribution range could be less than one well spacing $(200 \mathrm{~m})$ in the lacustrine strata, so correlation is unavailable. Such baffles have important influence on the fluid flow and remaining oil distribution during the water flooding stage in the oilfield.

The third-order muddy baffles are quite consistent within the same time interval as they were influenced by allogenic forcing (base level change). However, autogenic cycles can modify characteristics of allogenic ones, increasing the difficulty of interwell correlation. Specifically, when the autogenic forcing was intense to scour and erode allogenic interfaces, interwell correlation could be significantly difficult.

Therefore, it can be concluded that medium- and lowerorder muddy baffles are more difficult to correlate between wells than the higher-order ones and are associated with more uncertainties and multiple solutions.

\subsection{Stratigraphic development model and cross- well correlation}

Stratigraphers and development geologists have been working on a way to reduce the uncertainties and multiple solutions in the correlation of hierarchical muddy baffles (especially the lower-order ones). This study, attempting to solve such problems, proposed a conceptual mode to illustrate the development of hierarchical muddy baffles.

In terms of stratigraphic development modes, there are mainly five types, respectively, involving onlapping, denudation, retrogradation, progradation and accretion $(\mathrm{Wu}$ 2010). For deltaic deposits, progradation is more common (Fig. 5) (Olariu 2006; Ahmed et al. 2014; Tan et al. 2017).
In this context, muddy baffles should be correlated obliquely. However, it is critically necessary to figure out the scale of strata with the occurrence of such progradation. For instance, for the strata correlation along the provenance direction, there are two different results for the lower-order strata correlation when higher-order strata are horizontally correlated. Because both paleotopographical gradients and sediment-supply parameters could influence the stratigraphic model, gentler gradient and finer-grained sediments mean longer runout distance, and thus, the strata would dip more gently and should be horizontally correlated (Fig. 6a). On the contrary, in the successions with steeper gradient and coarser-grained sediments, lowerorder strata should be obliquely correlated (Fig. 6b). Similarly, if higher-order strata are obliquely correlated, there are also horizontal and oblique correlation ways for lowerorder ones (Fig. 6c, d). Therefore, it could be concluded that progradation should be present in hierarchical muddy baffles, which have also been demonstrated in the outcrop studies (Fig. 5). Such multiple solutions confuse the correlation of hierarchical muddy baffles among wells.

At present, the most commonly used methods to establish stratigraphic development modes are outcrop based and seismic data based. The former one is favored by the detailed observation and field measurement of target strata, which can help build very fine stratigraphic development models (especially for those medium- and lower-order strata which are hard to recognize). However, generally constrained by the outcropping conditions, higher-order strata are not that traceable, making it difficult to build the stratigraphic development mode. Moreover, most outcrops are in the periphery of basins, while the subsurface reservoirs beneath them could be deposited in slightly different environments, which makes the correlation difficult and even impossible. The latter method is favored by its capacity to show the $3 \mathrm{D}$ distribution of target subsurface strata. However, the limited vertical resolution hinders the reconstruction of medium- and lower-order strata such as 
those interfaces controlled by short-term and super-shortterm cycles, though higher-order strata can be recognized. Difficulties also lie in the deeply buried strata.

In order to overcome the above problems, this study proposed a new method to establish the stratigraphic development models, which could greatly reduce the uncertainties and multiple solutions in the interwell correlation of hierarchical muddy baffles (especially the lower-order ones).

\section{Cross-well muddy baffle correlation based on the hierarchical stratigraphic model}

In order to better correlate muddy baffles between wells, a strategy was proposed based on the hierarchical stratigraphic model. First, the foreset angles of hierarchical muddy baffles in the delta front during the deposition were constructed based on core analysis, and then, the stratigraphic development models of hierarchical muddy baffles were established, which can further guide the correlation of them between wells, especially for the medium- and lowerorder ones.
Fig. 6 Potential results of strata correlation in the delta front where three virtual wells are arrayed along the provenance direction with equal intervals. MSC and SSC, respectively, refer to the middle-term and short-term base level cycles, with the red and dark lines representing their respective boundaries. (a) Both MSC and SSC are horizontally correlated, representing accretion in the stratigraphic development model. (b) MSC are horizontally correlated, representing an accretion pattern; however, SSC are obliquely correlated corresponding to a progradation pattern. In addition, if MSC are obliquely correlated, there are also horizontal (c) and oblique (d) correlation ways for SSC

\subsection{Core-based calculation of muddy baffle foreset angles}

The foreset angles of hierarchical muddy baffles in the delta front can be calculated by core-based fine measurement and structural reconstruction of hierarchical muddy baffle base interface. Since core logging is widely used in reservoir analysis, this method is of general application. Specific steps are as follows.

First of all, the angle between the muddy baffle base (or top) interface and the vertical well trajectory line should be measured based on core data. According to the core-electric calibration, base (or top) interfaces of hierarchical muddy baffles should be identified in the core. Then, an interface without obvious erosion was selected to measure the angle between it and the vertical well trajectory line,
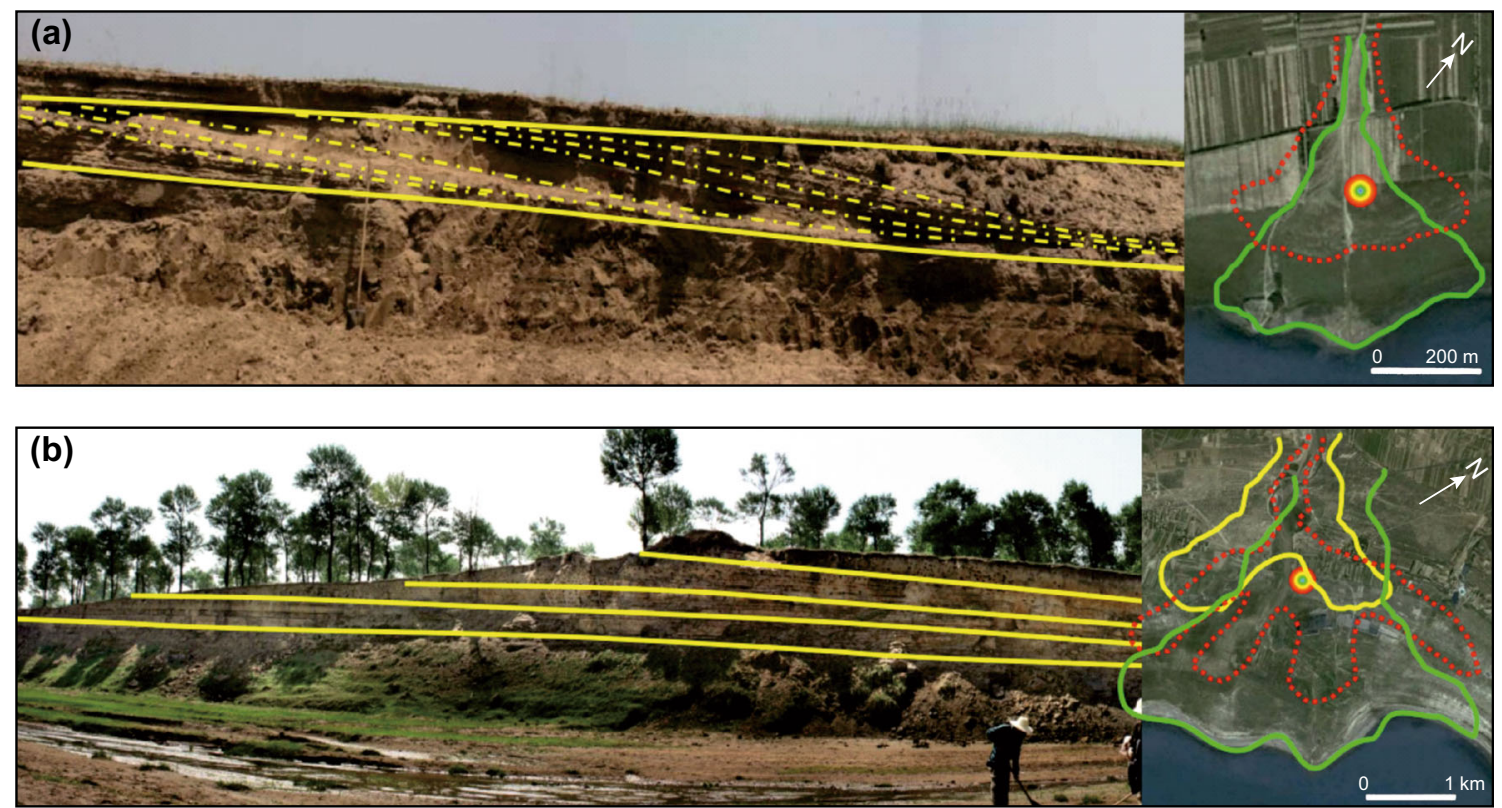

Fig. 5 Outcrop photographs showing the progradation of hierarchical stratigraphic units of lacustrine delta front facies in Daihai Lake, Inner Mongolia (provided by Xinghe Yu). a Within the single lobe, there is a noticeable progradation for the lobe elements whose boundaries are represented by yellow dashed lines. That means the fifth-order muddy baffles have a progradation pattern and should be obliquely correlated. b Also shown is the progradation pattern among multiple single lobes, with the yellow solid lines representing their boundaries. That indicates the fourth-order muddy baffles should also be obliquely correlated. The two insets companied with outcrops show the distributions of lobe elements (a) and single lobes (b) in the planform 

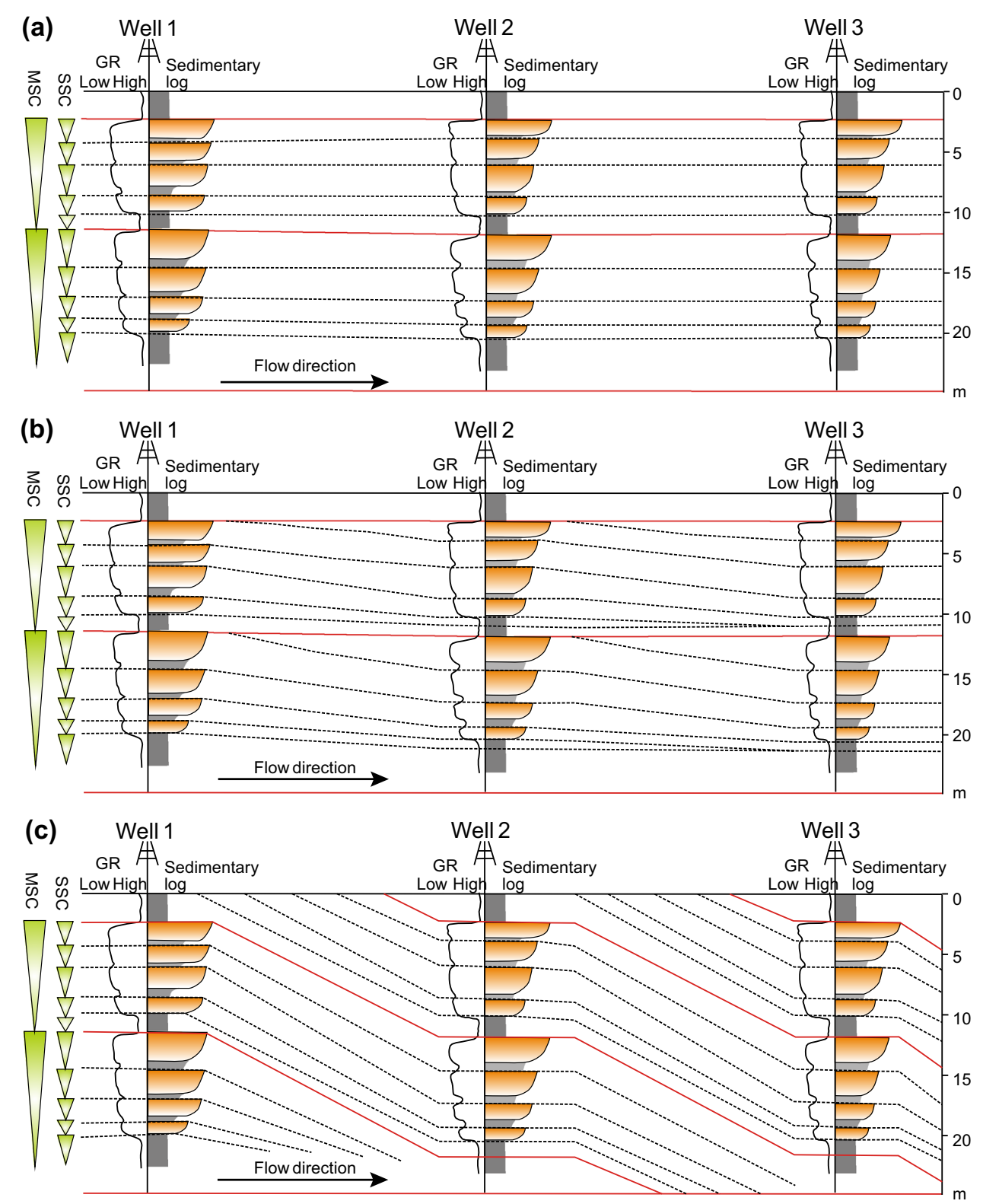
Low High log

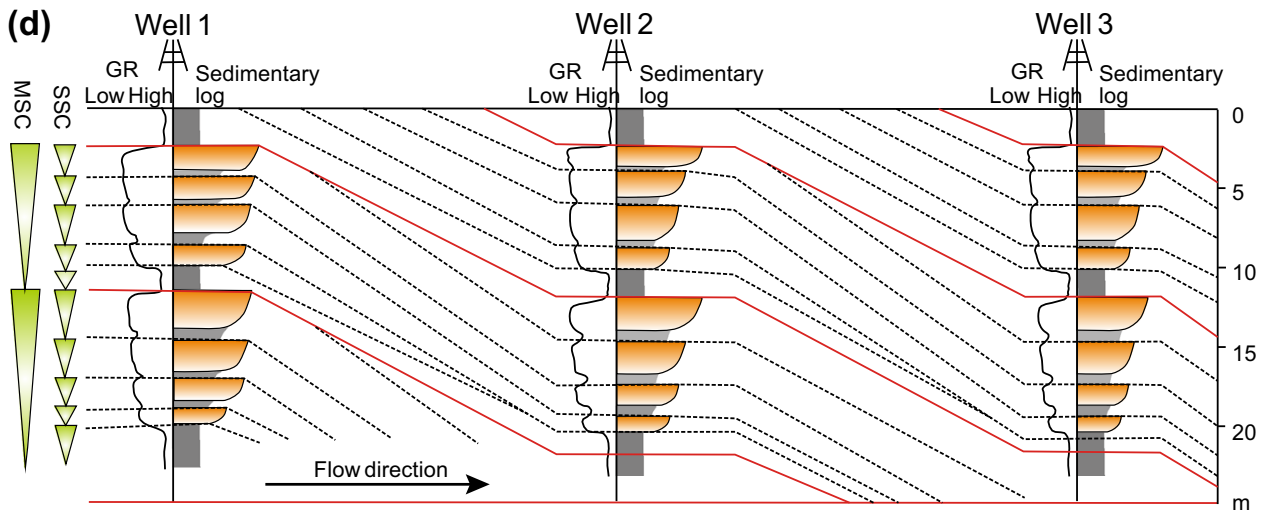




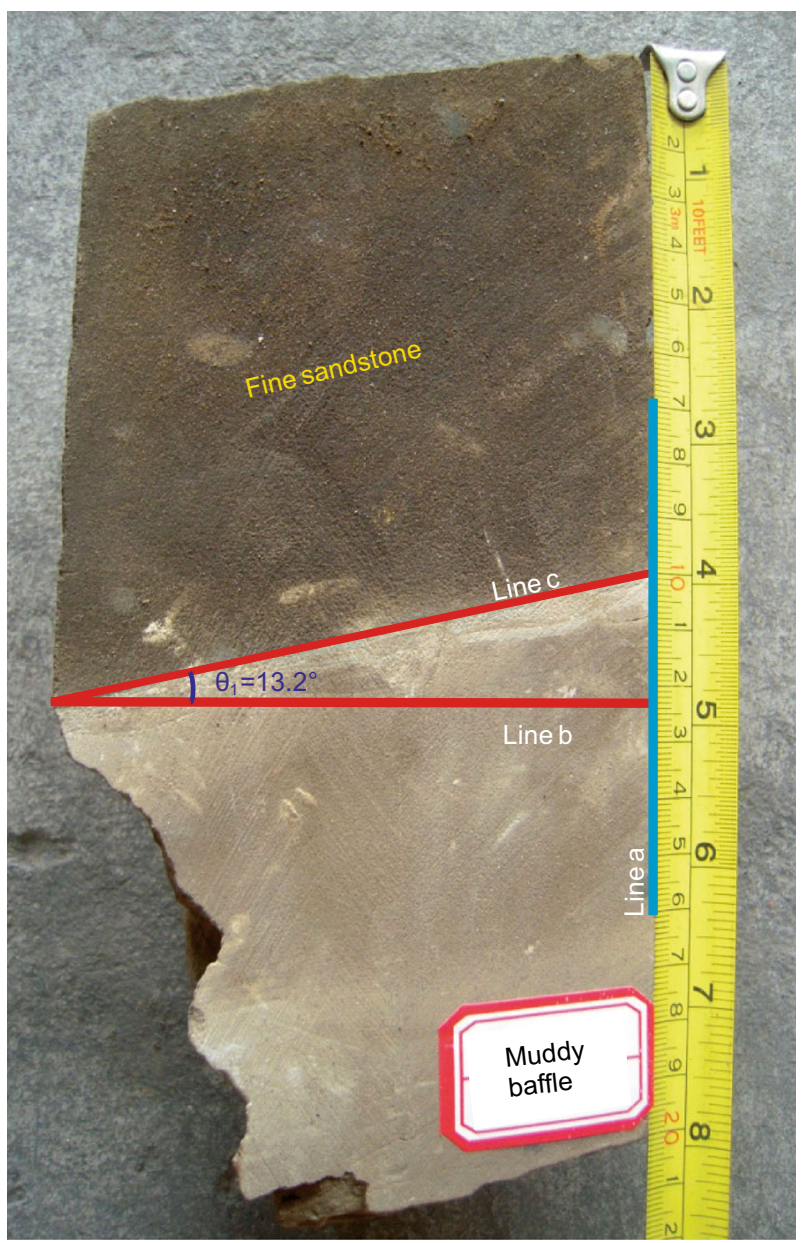

Fig. 7 Core photographs of a fifth-order muddy baffle from Well W3 showing the measurement of the angle between the muddy baffle top interface and vertical well trajectory line $\left(\theta_{1}\right)$. Lines $\mathrm{a}, \mathrm{b}, \mathrm{c}$ represent the well trajectory, vertical well trajectory line and top interface without obvious erosion, respectively, and the final calculated result of the $\theta_{1}$ is 13.2 degree

expressed as $\theta_{1}$. As shown in Fig. 7, a top interface of the muddy baffle was recognized in the core from Well W3 in the case study area and there is no obvious erosion between that interface and the above sandstones. Then, the angle between the top interface and the vertical well trajectory line is identified as $13.2^{\circ}$ in this case.

Then, the relationship between the sediment flow direction and the higher-order strata dipping direction could be identified, which could be either the same or contrary (Fig. 8). In the case study area, the higher-order strata correspond to the third-order sequence boundary, which is actually the top interface of $\mathrm{E}_{1} f_{1}$. As indicated by
Fig. 8 Schematic drawing showing the calculation of foreset angles of muddy baffles in the delta front during deposition. The calculation of the foreset angle can be divided into two major categories; the sediment flow direction (i.e., the muddy baffles dipping direction) and the higher-order strata dipping direction are the same (a) or are contrary (b). For these two major categories, they could be subdivided into three types according to the relationships among well types, well trajectory directions and high-order strata dipping directions; they, respectively, involve conditions of a vertical well (a1 and b1), the well trajectory dipping opposite (a2 and b2) and the same (a3 and b3) to that of the high-order strata

the structural contour map, the study area is a northwarddipping fault-nose structure (Fig. 1). The provenance is in the northwest, which means the relationship between muddy baffles and higher-order strata dipping direction is contrary, as the Case b in Fig. 8. At the same time, the structural dipping angle along the provenance direction in Well W3 is measured as $\theta_{2}=3.5^{\circ}$.

Meanwhile, the relationship among well types, well trajectory direction and formation occurrence should be analyzed, along with the deviation angle of the well trajectory from the vertical. For instance, Well W3 is an inclined well, with the trajectory from southeast to northwest. The drilling direction is contrary to the dipping direction of $\mathrm{E}_{1} f_{1}$ top interface (third-order sequence), corresponding to the Case b2 in Fig. 8. The deviation angle at the target layer is measured to be $\theta_{3}=16.1^{\circ}$.

Finally, the foreset angle $\theta_{x}$ of muddy baffles during deposition can be calculated according to the relationship between structural dipping, muddy baffle dipping, well pattern and well trajectory. Again, taking Well W3 as an example, both the drilling direction and the source flow direction are contrary to the strata dipping direction. Therefore, the calculation of foreset angles of muddy baffles corresponds to the Case b2 in Fig. 8 and the final result shows $\theta_{x}$ is about $0.6^{\circ}$.

\subsection{High-precision interwell correlation of muddy baffles guided by a stratigraphic development model}

According to the above methods, foreset angles of hierarchical muddy baffles can be calculated in the case study area, based on which hierarchical stratigraphic models can be established. Such models can provide important guidance to help achieve high-precision single-layer correlation in the target layers in certain wells. 


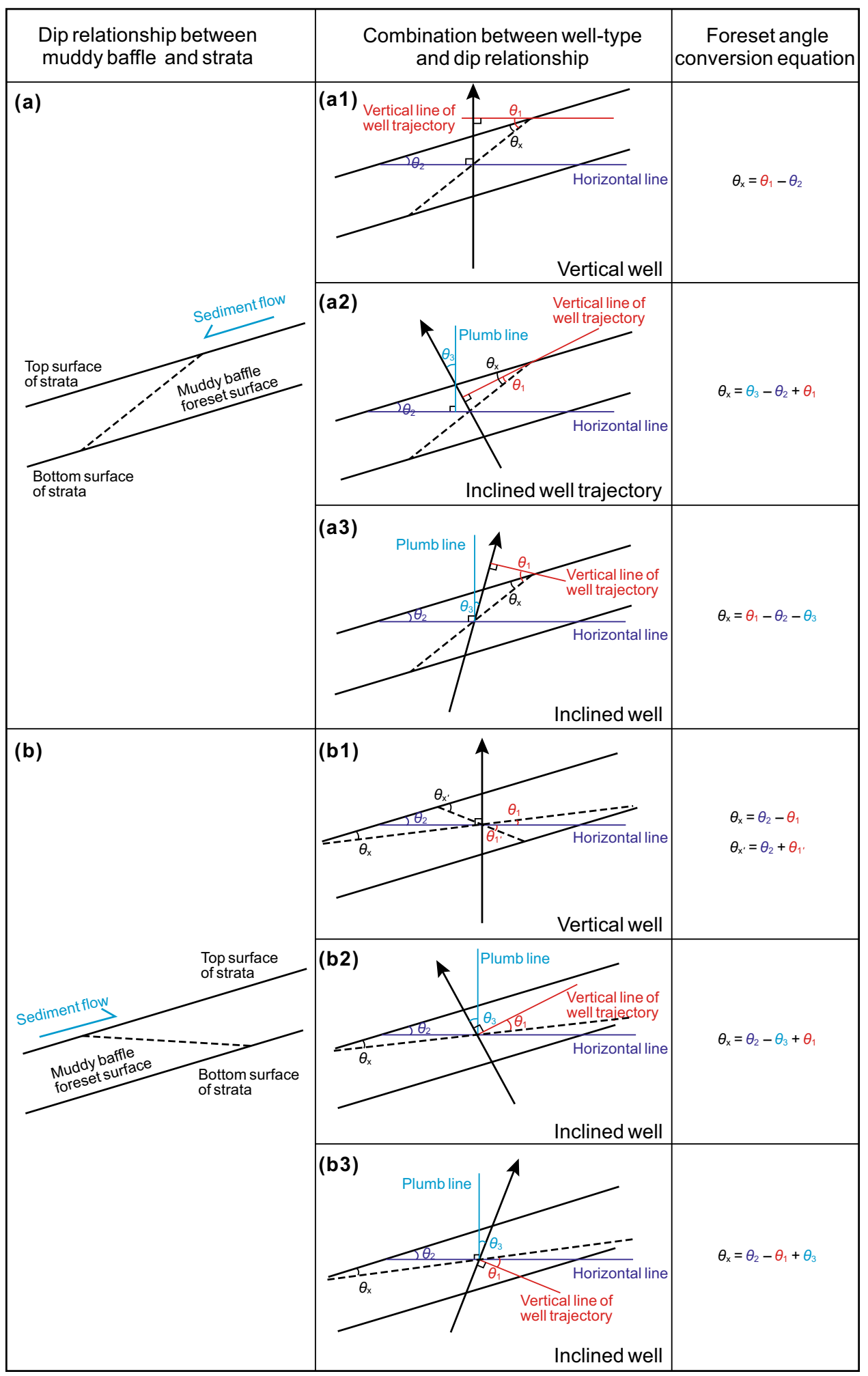

Note: $\theta_{1}$ is muddy baffle angle measured from core;

$\theta_{2}$ is stratigraphic dip;

$\theta_{3}$ is angle of well inclination;

$\theta_{x}$ is actual muddy baffle angle during deposition. 


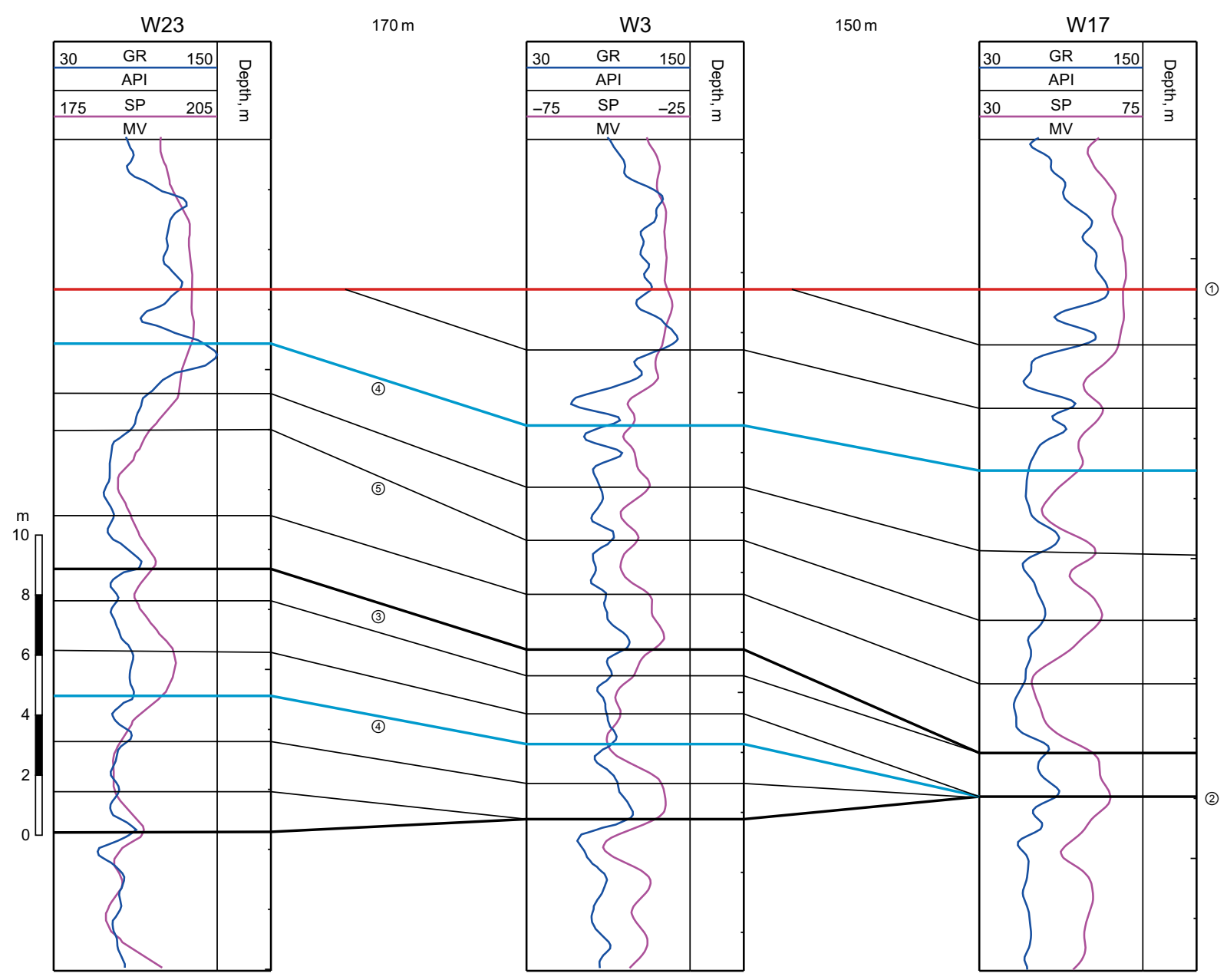

Fig. 9 Cross-well profile (W3 is the cored well) along the source direction showing the high-precision correlation of hierarchical muddy baffles. The numbers and line segments, respectively, represent the orders and the base of hierarchical muddy baffles. Note

The foreset angle calculation results indicate that there are different stratigraphic development models. The foreset angles of the first- and second-order muddy baffles are about $0^{\circ}-0.2^{\circ}$, which mean the horizontal correlation should be adopted (Figs. 9, 10); those of the third-order muddy baffles vary from $0.6^{\circ}$ to $1.7^{\circ}$, with most values larger than $1^{\circ}$, and accordingly, oblique correlation should be used (Fig. 9, 10), and those of the fourth- and fifth-order ones are $0.6^{\circ}-1.8^{\circ}$, suggesting oblique correlation (Figs. 9 , $10)$. Generally, the foreset angles are less than $2^{\circ}$, which are consistent with the sedimentary paleotopographical features of a Gilbert-type delta. that the first- and second-order baffles are horizontally correlated and other higher-order ones correspond to the oblique correlation. See the location of this profile in Fig. 1

Based on the foreset angle calculation results and the established stratigraphic development model, hierarchical muddy baffles were recognized in the un-cored wells by rock-electrical calibration. Furthermore, high-precision correlation of muddy baffles along the source direction can be implemented (Figs. 9, 10), results of which can be shown in the cross sections across the source direction. It is demonstrated that in the direction perpendicular to the provenance direction, the sedimentary units bounded by the first- to third-order muddy baffles present typical characteristics of compensating accumulation, while those by the fourth- and fifth-order muddy baffles show typical characteristics of accretion accumulation (Fig. 11), which are 


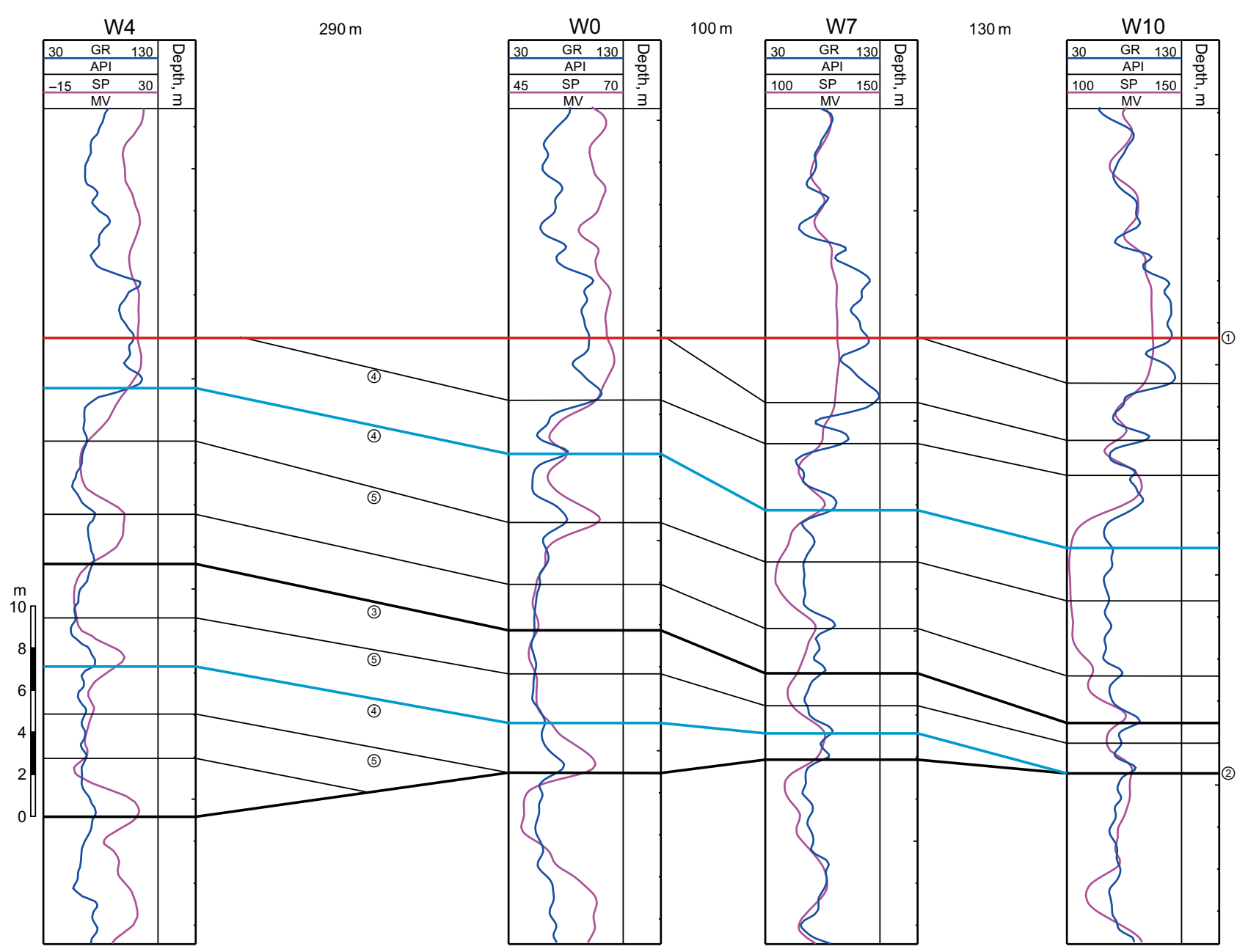

Fig. 10 Another cross-well profile (W0 is the cored well) along the source direction showing the high-precision correlation of hierarchical muddy baffles. Details are the same to that of Fig. 9, and the location of this profile is also shown in Fig. 1

in agreement with the sedimentary architecture characteristics of delta front deposits.

In order to further verify the reliability of the above results, new drilling and logging data were analyzed to investigate the injection-production effects. As shown in Fig. 12, Well W43 is the injection well, while Wells W9, W19 and W67 are production wells, among which Well W67 is a newly drilled production well since the reservoir was developed 11 years ago. There are four sand bodies in the target layer, with the upper one a dry layer, the middle two are oil layers, and the bottom is a water cut layer. The oilfield water analysis indicates that the water in the water cut layer at the bottom of Well W67 is from Well W43 rather than inherent formation water. It can be concluded that the injected water in the Well W43 can only spread to the bottom oil layers in the Well W67 due to the influence of obliquely distributed muddy baffles. The middle and upper three oil layers are not flooded. Therefore, it indirectly demonstrates that the oblique correlation works well in correlating the third- to fifth-order muddy baffles within
$\mathrm{E}_{1} f_{1}$ single layer, rather than the traditionally used horizontal correlation.

It can be concluded that the core-based foreset angle reconstruction method for muddy baffles in the delta front is relatively reliable, which can effectively guide the fine oil layer correlation within oil and gas reservoirs and thus play a significant role in more effective development and oil recovery enhancement of the oilfield.

\section{Conclusions}

1. The muddy baffles in $\mathrm{E}_{1} f_{1}$ can be classified into five orders which, respectively, have exclusive lithologic characteristics, log responses, scales and initiations. Also, different orders of muddy baffles have various degrees of difficulty when implementing cross-well correlation.

2. Higher-order ones (first- and second-order baffles) are controlled by allogenic cycles that resulted from large- 


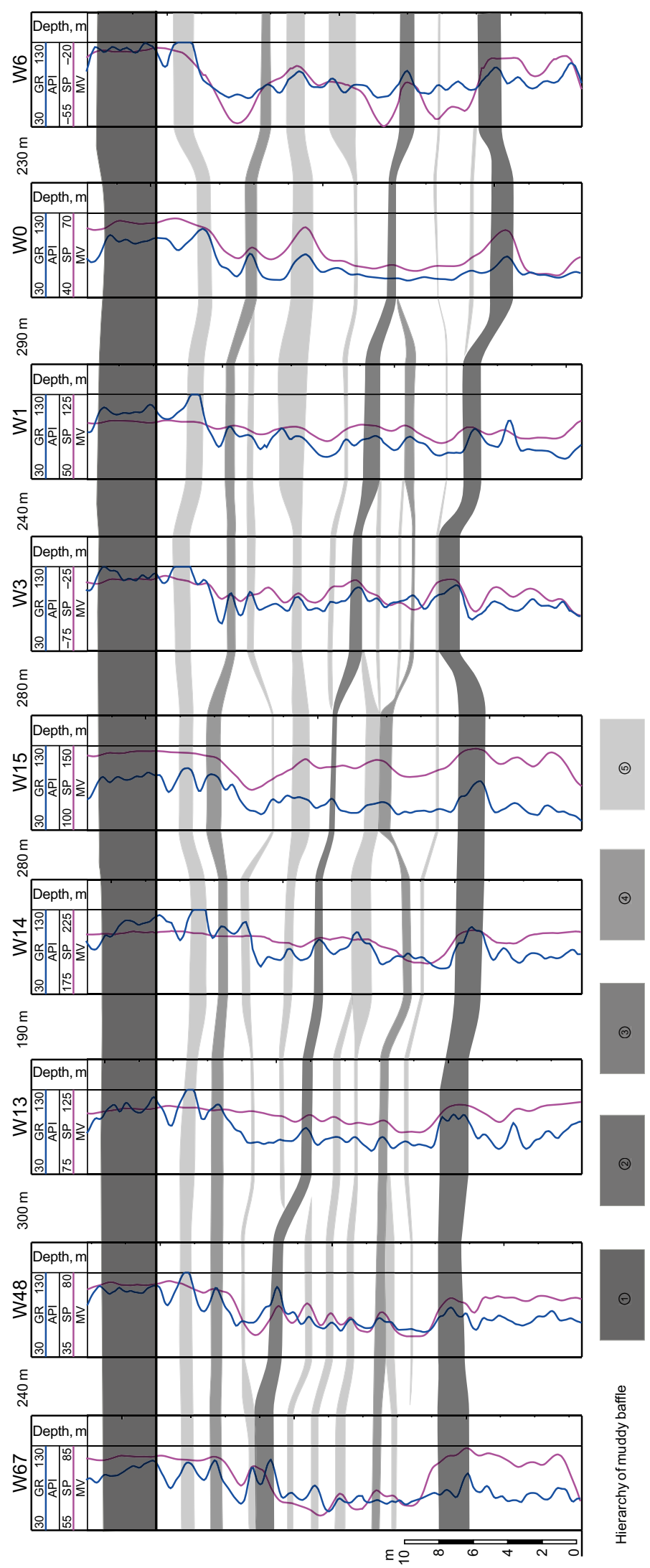

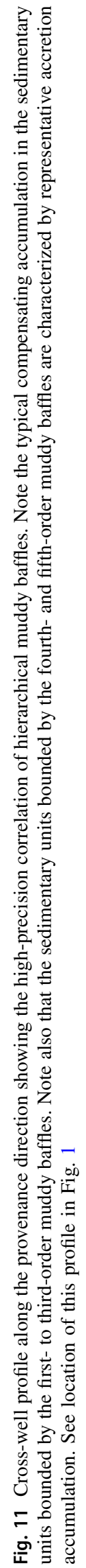




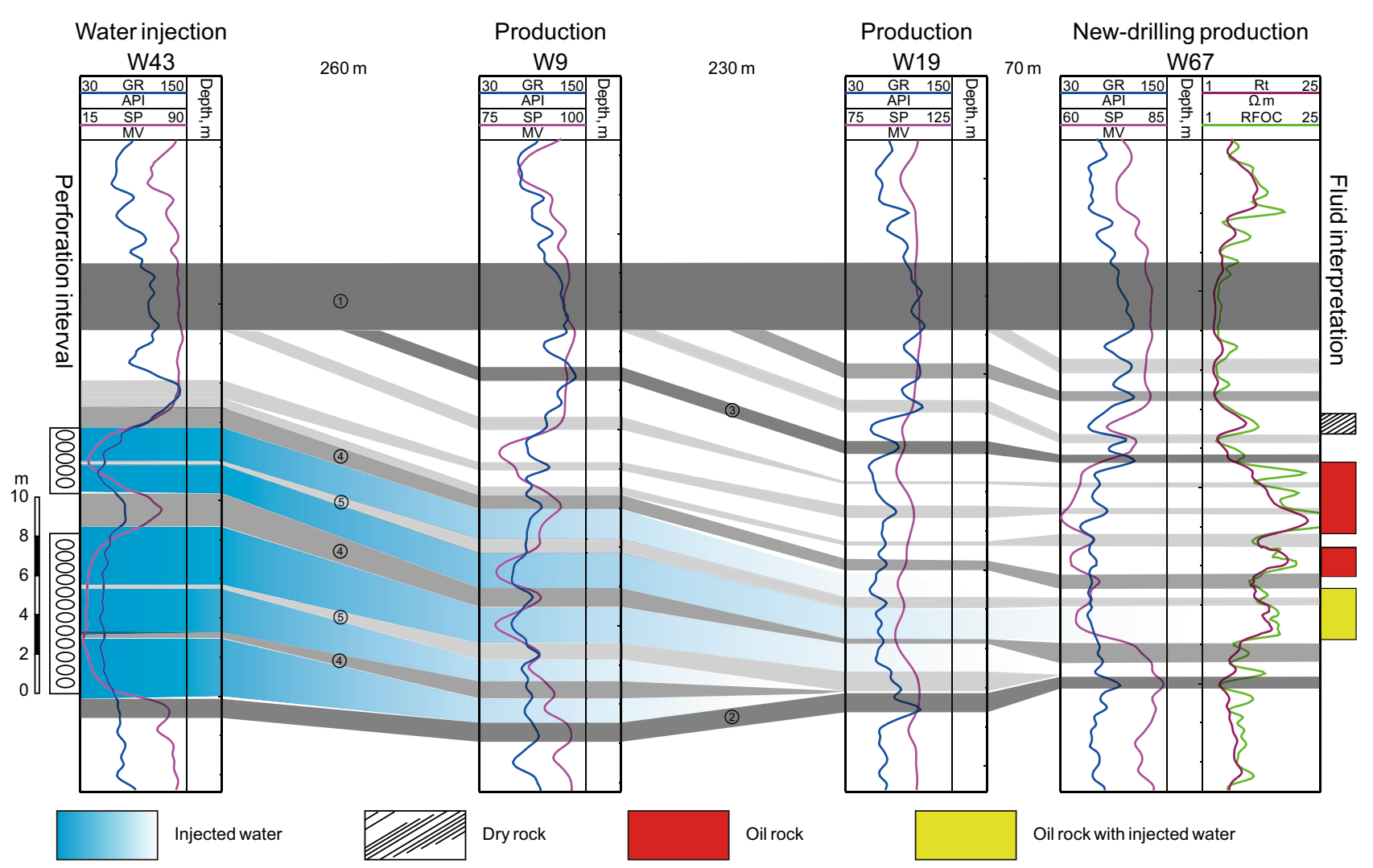

Fig. 12 Cross-well profile showing the injection-production effects under the control of hierarchical muddy baffles. W43 (injection well), W9 and W19 (production well) were all drilled in the early development stage, while W67 was the newly drilled production well since the reservoir was developed 11 years ago. For the four sand bodies encountered in drilling the target layer of W67, only the bottom one has been flooded by the injected water of W43. Location of this profile is also shown in Fig. 1 scale tectonic movements and climatic changes, and thus, they can be easily correlated between wells within the reservoir and even act as regional cap rocks; the third-order baffles are controlled by allogenic cycles modified by autogenic forcing, which are caused by local and temporary environment changes, and hence, they are more difficult to correlate; lowerorder ones (fourth- and fifth-order baffles), controlled by flow property changes and associated autogenic cycles, have smaller distribution areas and higher lateral discontinuity, causing multiple solutions in the cross-well correlation of them.

3. Under the direction of a stratigraphic development model, the correlation of hierarchical muddy baffles could significantly reduce the uncertainties and multiple solutions. Therefore, well-constructed stratigraphic models are critical. Traditional methods to establish the stratigraphic development model are based on outcrops or seismic data, which, however, are very hard to build due to the insufficient abundance or accuracy of these data. A new method, based on core analysis, was proposed in this study to construct the stratigraphic model, which could efficiently solve this crucial issue.

4. During the core analysis, it is most significant to reasonably calculate foreset angles of muddy baffles during deposition. Firstly, efforts should be made to identify the muddy baffle base (or top) interface and measure its dipping angle (the angle between the interface and vertical well trajectory line, referred to here as $\theta_{1}$ ); then, the relationship between muddy baffle and high-order strata dipping direction (being either the same or contrary) should be recognized and the dipping angle of high-order strata $\left(\theta_{2}\right)$ should be measured; according to the previously mentioned information, along with the analysis of well types and measurement of the hole deviation angle $\left(\theta_{3}\right)$, the corresponding foreset angles of muddy baffles $\left(\theta_{x}\right)$ could be accurately calculated.

Acknowledgements This study is supported by an Open Fund of State Key Laboratory of Oil and Gas Reservoir Geology and Exploitation (Southwest Petroleum University, PLN1503), the National Natural Science Foundation of China (Nos. 41602145, 41402125, and 
41602117), Scientific Research Starting Project of SWPU (No. 2014QHZ008).

Open Access This article is distributed under the terms of the Creative Commons Attribution 4.0 International License (http://creative commons.org/licenses/by/4.0/), which permits unrestricted use, distribution, and reproduction in any medium, provided you give appropriate credit to the original author(s) and the source, provide a link to the Creative Commons license, and indicate if changes were made.

\section{References}

Ahmed S, Bhattacharya JP, Garza DE, et al. Facies architecture and stratigraphic evolution of a river-dominated delta front, Turonian Ferron sandstone, Utah, USA. J Sediment Res. 2014;84(2):97-121. https://doi.org/10.2110/jsr.2014.6.

Ainsworth RB, Sanlung M, Duivenvoorden STC. Correlation techniques, perforation strategies, and recovery factors: an integrated 3-D reservoir modeling study, Sirikit Field, Thailand. AAPG Bull. 1999;83(10):1535-51.

Bao HY, Guo ZF, Huang YP, et al. Tectonic-thermal evolution of the Subei Basin since the Late Cretaceous. Geol J China Univ. 2013;4:574-9. https://doi.org/10.3969/j.issn.1006-7493.2013.04. 002 (in Chinese).

Cross TA, Baker MR, Chapin MA, et al. Application of high resolution sequence stratigraphy to reservoir analysis. In: England: 7th IFP Exploration and Production Research Conference-Subsurface Reservoir Characterization from Outcrop Observations. 1992. p. 1-33.

Escalona A, Mann P. Sequence-stratigraphic analysis of Eocene clastic foreland basin deposits in central Lake Maracaibo using high-resolution well correlation and 3-D seismic data. AAPG Bull. 2006;90(4):581-623. https://doi.org/10.1306/ 10130505037.

Geehan GW, Lawton TF, Sakurai S, et al. Reservoir characterization. London: Academic Press; 1986. p. 63-82.

Guo JX. Interlayer distribution model in delta front sub facies sandbody of Member II of Shahejie Formation in Dongying Depression, China. J Chengdu Univ Technol. 2011;38(1):15-20. https://doi.org/10.3969/j.issn.1671-9727.2011.01.003

(in
Chinese)

Jackett SJ, Jobe ZR, Lutz BP, et al. Detecting baffle mudstones using microfossils: an integrated working example from the Cardamom Field, Block 427 Garden Banks, Gulf of Mexico. Palaeogeogr Palaeoclimatol Palaeoecol. 2014;413:133-43. https://doi.org/10.1016/j.palaeo.2014.04.007.

Jackson MD, Muggeridge AH. Effect of discontinuous shales on reservoir performance during horizontal water flooding. SPE J. 2000;5(4):446-55. https://doi.org/10.2118/69751-PA.

Ji YL, Lu H, Liu YR. Sedimentary model of shallow water delta and beach bar in the Member 1 of Palaeogene Funing Formation in Gaoyou Sag, Subei Basin. J Palaeogeogr. 2013;15(5):729-40. https://doi.org/10.7605/gdlxb.2013.05.060 (in Chinese).

Ji YL, Wu SH, Zhang R. Recognition of auto-cycle and allo-cycle and its role in strata correlation of reservoirs. J China Univ Pet. 2012;36(4):1-6. https://doi.org/10.3969/j.issn.1673-5005.2012. 04.001 (in Chinese).

Larue DK, Legarre H. Flow units, connectivity, and reservoir characterization in a wave-dominated deltaic reservoir: Meren reservoir, Nigeria. AAPG Bull. 2004;88(3):303-24. https://doi. org/10.1306/10100303043.

Li H, White CD. Geostatistical models for shales in distributary channel point bars (Ferron Sandstone, Utah): from ground- penetrating radar data to three-dimensional flow modeling. AAPG Bull. 2003;87(12):1851-68. https://doi.org/10.1306/ 07170302044.

Li YH, Wu SH, Li YP, et al. Hierarchical boundary characterization of delta front mouth bar reservoir architecture. J Oil Gas Technol. 2007;29(6):49-52. https://doi.org/10.3969/j.issn.10009752.2007.06.011 (in Chinese).

Liu JH, Qiao L, Wu LF. Characteristics and developmental model of the Funing Formation seismite in the Matouzhuang Oilfield, Subei Basin. J Geol. 2016;40(2):247-52. https://doi.org/10.3969/ j.issn.1674-3636.2016.02.247 (in Chinese).

Miall AD. Architectural elements and bounding surfaces in fluvial deposits: anatomy of the Kayenta Formation (lower Jurassic), Southwest Colorado. Sediment Geol. 1988;55(3):233-62. https:// doi.org/10.1016/0037-0738(88)90133-9.

Olariu C. Terminal distributary channels and delta front architecture of river-dominated delta systems. J Sediment Res. 2006;76(76):212-33. https://doi.org/10.2110/jsr.2006.026.

Qian J. Oil and gas fields formation and distribution of Subei Basinresearch compared to Bohai Bay Basin. Acta Pet Sin. 2001;22(3):12-21 (in Chinese).

Qiu HJ, Xu ZQ, Qiao DW. Progress in the study of the tectonic evolution of the Subei basin, Jiangsu, China. Geol Bull China. 2006;25(9):1117-20. https://doi.org/10.3969/j.issn.1671-2552. 2006.09.023 (in Chinese).

Shu QL. Interlayer characterization of fluvial reservoir in Guantao Formation of Gudao Oilfield. Acta Pet Sin. 2006;27(3):100-3. https://doi.org/10.3321/j.issn:0253-2697.2006.03.022 (in Chinese).

Smart KJ, Ferrill DA, Morris AP. Impact of interlayer slip on fracture prediction from geomechanical models of fault-related folds. AAPG Bull. 2009;93(11):1447-58. https://doi.org/10.1306/ 05110909034.

Tan CP, Yu XH, Liu B, et al. Conglomerate categories in coarsegrained deltas and their controls on hydrocarbon reservoir distribution: a case study of the Triassic Baikouquan Formation, Mahu Depression, NW China. Pet Geosci. 2017;23(4):403-14. https://doi.org/10.1144/petgeo2016-017.

Tripsanas EK, Bryant WR, Phaneuf BA. Depositional processes of uniform mud deposits (unifites), Hedberg Basin, northwest Gulf of Mexico: new perspectives. AAPG Bull. 2004;88(6):825-40. https://doi.org/10.1306/01260403104.

Vail PR. Atlas of seismic stratigraphy. Oklahoma: American Association of Petroleum Geologists; 1987. p. 1-10.

Weber KJ. Reservoir characterization. London: Academic Press; 1986. p. 487-544.

Willis BJ, White CD. Quantitative outcrop data for flow simulation. J Sediment Res. 2000;70(4):788-802. https://doi.org/10.1306/ 2DC40938-0E47-11D7-8643000102C1865D.

Wu D, Zhao D, Zhu X, et al. Sedimentology and seismic geomorphology of a lacustrine depositional system from the deep zone of the Gaoyou Sag, Subei Basin, eastern China. Aust J Earth Sci. 2017;64(2):265-82. https://doi.org/10.1080/08120099.2017. 1279213.

Wu SH. Reservoir characterization \& modeling. Beijing: Petroleum Industry Press; 2010. p. 134-69 (in Chinese).

Yin KG, Chen G, Qian GR, et al. Sedimentary facies and sand body distribution of the 1st and 2nd sub-members in first member of Funing Formation in Gaoyou Sag. Complex Hydrocarb Reserv. 2009;2(3):20-4 (in Chinese).

$\mathrm{Xu} \mathrm{Y,} \mathrm{Xu} \mathrm{HM,} \mathrm{Guo} \mathrm{CT,} \mathrm{et} \mathrm{al.} \mathrm{Origin,} \mathrm{characteristics} \mathrm{and} \mathrm{effects} \mathrm{on}$ oilfield development of interlayer of shore sandstone reservoir in Tazhong area. Sci Technol Rev. 2012;30(15):17-21. https://doi. org/10.3981/j.issn.1000-7857.2012.15.001 (in Chinese).

Zhang CM, Yin TJ, Zhang SF, et al. Hierarchy analysis of mudstone barriers in Shuanghe Oilfield. Acta Pet Sin. 2004;25(3):48-52. 
https://doi.org/10.3321/j.issn:0253-2697.2004.03.009

(in Chinese).

Zhao L, Liang HW, Zhang XZ, et al. Relationship between sandstone architecture and remaining oil distribution pattern: a case of the
Kumkol South Oilfield in South Turgay Basin, Kazakhstan. Pet Explor Dev. 2016;43(3):433-41. https://doi.org/10.11698/ped. 2016.03.14 (in Chinese). 